This is the peer reviewed version of the following article: Brittain, K., Degnen, C., Gibson, G., Dickinson, C. and Robinson, L. (2017), When walking becomes wandering: representing the fear of the fourth age. Sociology of Health and Illness, 39: 270-284, which has been published in final form at https://doi.org/10.1111/1467-9566.12505 This article may be used for noncommercial purposes in accordance With Wiley Terms and Conditions for selfarchiving. 


\section{When does walking become wandering - representing the fear of the fourth age?}

\begin{tabular}{|r|l|}
\hline Journal: & Sociology of Health and Illness \\
\hline Manuscript ID & SHI-00221-2015.R1 \\
\hline Manuscript Type: & Original Article \\
\hline Subject Area: & $\begin{array}{l}\text { Ageing < RESEARCH AREAS, Dementia / Alzheimer's < RESEARCH AREAS, } \\
\text { Place < RESEARCH AREAS }\end{array}$ \\
\hline $\begin{array}{l}\text { Dementia is linked to behavioural changes that are perceived as } \\
\text { challenging to care practices. One such behavioural change is 'wandering', } \\
\text { something that is often deeply feared by carers and by people with } \\
\text { dementia themselves. Understanding how behavioural changes like } \\
\text { wandering are experienced as 'problematic' is critically important in current } \\
\text { discussions about the behavioural and psychological symptoms of } \\
\text { dementia. In this paper we draw on our secondary analysis of qualitative } \\
\text { interviews and focus groups with carers of people with dementia to } \\
\text { examine the question 'when does walking become wandering'? Drawing on } \\
\text { theoretical perspectives from anthropology, sociology and human } \\
\text { geography to explore experiences of carers and of people with dementia, } \\
\text { we argue that a conceptual shift occurs in how pedestrian activity is } \\
\text { represented as something purposeful, meaningful and healthy (walking) to } \\
\text { something threatening and that needs managing (wandering). We } \\
\text { demonstrate how this shift is connected to cultural assumptions about the } \\
\text { mind/body relationship in both walking and in dementia. We further argue } \\
\text { that the narratives of carers about wandering challenge the notion of } \\
\text { 'aimless' walking within the fourth age. This is because, evident within } \\
\text { these narratives, there are often pronounced links to specific areas and } \\
\text { meaningful places where people with dementia walk to. }\end{array}$ \\
\hline
\end{tabular}




\title{
When does walking become wandering - representing the fear of the fourth age?
}

\begin{abstract}
Dementia is linked to behavioural changes that are perceived as challenging to care practices. One such behavioural change is 'wandering', something that is often deeply feared by carers and by people with dementia themselves. Understanding how behavioural changes like wandering are experienced as 'problematic' is critically important in current discussions about the behavioural and psychological symptoms of dementia. In this paper we draw on our secondary analysis of qualitative interviews and focus groups with carers of people with dementia to examine the question 'when does walking become wandering'? Drawing on theoretical perspectives from anthropology, sociology and human geography to explore experiences of carers and of people with dementia, we argue that a conceptual shift occurs in how pedestrian activity is represented as something purposeful, meaningful and healthy (walking) to something threatening and that needs managing (wandering). We demonstrate how this shift is connected to cultural assumptions about the mind/body relationship in both walking and in dementia. We further argue that the narratives of carers about wandering challenge the notion of 'aimless' walking within the fourth age. This is because, evident within these narratives, there are often pronounced links to specific areas and meaningful places where people with dementia walk to.

Main Body word count 8747
\end{abstract}

\section{Keywords}

Dementia, Wandering, Fourth Age, Walking, Place attachment, Sense of place, Mind/body, Technology

\section{Background}




\section{Wandering and dementia}

Dementia, although a contested category (Moreira and Bond 2008), is on the increase (Department of Health 2009). Dementia is an umbrella term encompassing a number of subtypes of cognitive impairment (including vascular, Lewy body and fronto-temporal) that have been linked with a series of specific behavioural changes as the 'disease' progresses. One such behavioural change is 'wandering'. Wandering' is a behaviour that occurs frequently (Klein et al 1999, Chan et al 2003); one in five people with dementia are said to wander (Wick and Zanni 2006). It is a behaviour that has often been labelled under the term agitation or agitated behaviour (Cohen-Mansfield 1986) and is viewed within dementia care as the most challenging to manage (Lai and Arthur 2003). It has also been shown to cause considerable carer distress and it can often trigger early institutionalisation (Balestreri et al 2000, Phillips and Diwan 2003).

Whilst wandering is viewed as a behaviour that carries with it significant risk of harm for the person with dementia, the actual level of risk of a significant injury (or death) has been shown to be around 5\% (Rowe and Glover 2001). For instance, out of 615 reported incidents of people with dementia in the state of Florida becoming 'lost', four people died (three from hypothermia, one from a train accident) and a further thirty people sustained significant injuries (including skin and head injuries, dehydration and hypothermia) (Rowe and Glover 2001). However, although the percentage of people with dementia harmed from wandering is low, families and carers of people with dementia experience intense anxiety about the risk of the person with dementia becoming lost. Indeed, people with dementia who have talked about their experience of feeling lost have also reported fears of this behaviour

'Losing oneself', figuratively and literally, is often evoked in everyday discourse as a marker of when 'real' old age can be said to begin (_), the onset of the feared 'fourth 
age' (Gilleard and Higgs 2011).

We propose that understanding how and why some behavioural changes are perceived as 'problematic' or 'challenging' is a crucial issue in the current discussions over what is termed 'behavioural psychological symptoms of dementia', or BPSD. The "voices of those who have experiential expertise of dementia and wandering" are neglected and are needed to shape future research and practice (Dewing 2006: 239). Our exploration of when walking comes to be understood as wandering adds to these discussions in precisely this way, focusing on experiential and everyday perspectives on these matters.

\section{What does wandering mean?}

Wandering has been discussed within the healthcare literature since the 1970s (Halek and Bartholomeyczik 2012: 406). In earlier years of these debates, wandering was defined as "a tendency to move about, either in a seemingly aimless or disoriented fashion, or in pursuit of an indefinable or unobtainable goal" (Snyder et al 1978: 272). This definition and others that focus on the 'aimlessness' of wandering have however increasingly come under scrutiny (Halek and Bartholomeyczik 2012, Algase 1997, 1999, Lucero 2002). Indeed, not only is "the aetiology of wandering poorly understood" but it also "remains an unresolved riddle" (Cipriani et al 2014: 137). Although wandering is clinically recognised, there is no standard definition (Cipriani et al 2014), with one review identifying seventy different definitions used within this research field (Dewing 2006: 241).

When attempts are made to define wandering, however, most fall into one of two broad camps. As highlighted by Halek and Bartholomeyczik (2012) in their review of the state of the field, these are, firstly, a person centred care approach where wandering is viewed as a derogatory term; and secondly, an approach that views wandering as a normal human activity. In the latter case, wandering is argued to be understandable, and to be a 
"consequence of a search for something familiar, safe and pleasant" (Coltharp et al 1996 cited in Halek and Bartholomeyczik 2012: 406). Attempts to define specifically what wandering is are further hampered by the complexity of behaviours attributed to it (Lai and Arthur 2003, White and Montgomery 2014) as well as difficulties in articulating appropriate theoretical frameworks for analysis. Indeed Algase, a leading figure in debates over wandering, reports that over half the research published in this area lacks any theoretical framework altogether (2006).

Evident in these ongoing debates is thus the complexity of how to define precisely what wandering is, the kinds of wandering that occur, the behaviours associated with it, the usefulness of the term itself, and appropriate theoretical tools to analyse it. There also is no agreement over the issue of intentionality of the person with dementia, with wandering seen to be both 'aimless' and 'directed': the "extent [to which] wandering is random and aimless or goal-oriented and planned cannot be clarified" (Halek and Bartholomeyczik 2012: 407). Some have sought to differentiate between 'normal walking' and wandering by classifying wandering in four ways: lapping, pacing, random travel and direct travel (Algase et al 1997) whilst others have argued for the need to reconceptualise wandering as "a natural form of activity", positing the possibility of "generating other forms of theoretical descriptions and explanations" (Dewing 2006: 245) via "the meshing of research with other disciplines such as human geography, architectural and environmental design" (Dewing 2006: 240). Wandering is thus a notoriously tricky category to pin down, one that eludes easy categorisation in the healthcare literature. As such, it may not be surprising that the term wandering itself is viewed by some as outdated altogether (Maher 2001).

Walking: more than 'just exercise,

In stark contrast to the negative associations around wandering is 'walking'. Walking is 
viewed as an activity that brings with it numerous health benefits, and is included in recommended guidelines on how beneficial exercise is for older adults (Nelson et al 2007). But walking is also valorised in a growing social science literature focusing on mobilities. This literature includes researchers in human geography, anthropology and sociology, with scholars considering walking from a variety of perspectives ${ }^{\mathrm{ii}}$. Important lessons from this literature include, for example, the importance of walking for producing experience of place (Middleton 2011) and in turn enhancing a sense of place attachment and facilitating everyday sociality (Bean et al 2008). This emergent body of literature makes clear that pedestrian activity should not be dismissed as a banal form of transport from one point to another, nor is walking simply an issue of health, but instead is linked to people's relationships with each other and with place.

Also revealing are popular understandings of walking in Western ${ }^{\mathrm{iii}}$ societies, understandings which have a long history of moralising. On the one hand, walking has been perceived as "tedious and commonplace, a view that lingers in the residual connotations of the word 'pedestrian"” (Ingold 2004: 321); on the other hand, walking, when done 'properly' (see Edensor 2000: 87-99), has long been attributed with the power to free the mind to higher planes of contemplation, permitting the "connections between human mind and sublime nature" (Michael 2000: 110). Additionally, some kinds of walking are understood as appropriate and others, not: schoolchildren travelling between school and home, commuters, and the flaneur's "leisurely stroll" all are seen as legitimate, in contrast with "the slow wanderings of the unemployed and homeless" (Edensor 2010: 69). So, in sum: walking can be done both 'correctly' and 'incorrectly'. When not done properly, walking is socially stigmatising, and some incorrect walking becomes wandering. 
But this still leaves us with the question we set out with: when does walking become wandering? In partial response, it is worth noting that some wandering - but not all - is seen as respectable. Correct walking is understood to be mindful, rational, controlled, and cultured: the epitome of the modern subject. Respectable forms of wandering are also perceived as 'cultured', such as the flaneur and the tourist. However, to return to our question, stigmatised wandering is often signalled in relation to problematic forms of temporality and problematic forms of embodiment. This stigmatised form of wandering is perceived as childlike, unthinking, non-rational and closer to a state of nature whereby the body takes over the mind.

Whilst the walking and mobilities literature is bourgeoning, accounts of non-normative, everyday pedestrian activity are still acutely missing from it (Andrews et al 2012; Middleton 2010), including wandering. We posit that wandering is one of these forms of non-normative walking which requires careful attention. We seek to explore how what is revealed in these non-normative forms of pedestrian activity are the ways in which "mobility and movement are entangled with relations of power, identity and embodiment" (Spinney 2010:7, cited in Middleton 2011) which have too often been ignored in the case of people with dementia and which demand a fuller accounting. For instance, evident in Western understandings of pedestrian activity is the notion that walking and thinking are connected. Rhythms of walking are understood to be bound up with thinking, and different rhythms of walking can generate different ways of thinking (Middleton 2009 cited in Edensor 2010: 73). That walking is linked to the thinking, modern self (Edensor 2000: 84) but wandering by the person with dementia should be associated with a pathological mind/body relationship is not, we suggest, incidental. This is a point we will return to, below.

\section{Aim of paper}


In this paper, we pose the question "when does walking become wandering?" We draw on qualitative research with carers of people with dementia, investigating a series of interrelated issues around the fourth age and the social representation of dementia whereby a perceptible shift occurs. In this context, understandings of walking change from a healthy activity and something that is aspired to in 'successful' ageing to a behaviour that is viewed with fear and which comes to have deeply negative consequences in terms of care. This shift arguably further marginalises people with dementia from the ability to participate in the "emancipatory capacities of city spaces" (Middleton 2011: 93) and the social networks and place attachment facilitated by walking (Bean et al 2008), characteristics that are linked with an enhanced sense of wellbeing. As a corrective to these cultural assumptions about pedestrian activity for people with dementia, we focus on how carers 'produce' pedestrian activity as wandering. Our paper highlights - from the perspective of carers - narratives around wandering and stories of the person with dementia becoming lost. These narratives, we argue, in actual fact challenge the notion of aimless, un-thinking or non-purposeful walking within the fourth age precisely because they highlight ties to specific areas where people with dementia walk to. We attend to the importance of place, as signalled above by Edensor and Bean et al, asking what happens to the relationship between body and place when the focus shifts from walking to wandering in carer's accounts. This permits us to contribute to the evolving debates over the behaviour of people with dementia: our material problematizes and unsettles the terms and normative perspectives on such behaviour; calls attention to the broader cultural issues that underpin and reinforce assumptions about wandering; and opens up space to consider other perspectives on the question of when is a behaviour a 'challenging' or 'problematic' one.

\section{Methods}


This paper is based on qualitative data derived from two studies that explored the experience of carers of people with dementia and the use of assistive technology, within and outside of the home. The interviews touched on their views of accessing outside spaces and whether or not they used technology to support the person with dementia to carry on with activities in and outside of the home. Results from these individual studies have been published previously but here we draw on as of yet unpublished narratives of carers. This paper specifically focuses on the carers' experiences of managing getting out and about with the person with dementia. Although not specifically about 'wandering' or 'place attachment', both of these concepts repeatedly appeared in the carers' narratives. As such, they offer valuable insights into both the experiences of carers and people with dementia that help unpack and critically examine the cultural ideas at work around understandings of the perceived transformation from walking to wandering.

An inductive approach to data collection was adopted in both studies, using the constant comparative method (Glaser 1965) and deviant case analysis. In total there were three focus groups with 11 carers and 26 one-to-one interviews with carers. Both the focus group discussions and interviews lasted approximately one hour, and all were digitally recorded, transcribed verbatim and anonymised. The focus groups were held in familiar surroundings to ensure a sense of continuity and familiarity for the participants. These were facilitated by , and took place in different settings within the community (church, residential home, Alzheimer's Society). Participants were recruited from two local branches of the Alzheimer's Society in two North of England coastal towns. The interviews took place in a room on the University campus or the person's home, depending on what was most convenient for the interviewee. All recruitment strategies and interaction with participants have followed strict ethical guidelines, complying with the British Society of Gerontology's guidelines on ethical research (BSG 2008). Participation was voluntary and participants were told that they could 
opt out at any stage of the research process. Ethical approval for both studies was sought and given through the University Ethics Committee.

For this paper, we have explored the question 'when does walking become wandering' and highlight both the tension surrounding the 'fear' of the person being cared for becoming 'lost' alongside the recognition of outside activities that those being cared for want to participate in. In answering this question $\square$ and $\square$ undertook a secondary analysis ${ }^{\mathrm{iv}}$ of the two datasets, by revisiting previously coded sections of data that specifically related to 'wandering' or 'walking' from the perspective of carers of people with dementia.

\section{Findings \\ Fear of losing them}

Carers were explicit about the sense of responsibility and generalised sense of worry they often experienced as they became more aware of the potential of losing the person with dementia. This is something they fear deeply:

"I know other people have had to worry about people who have gone missing, but its when you actually live through it and you think 'God, what's happened to him', and he had completely forgotten within 5 minutes that he had been missing, but I hadn't, I still, even when he is just at his day care, I am on edge the whole time, because I am thinking, 'is he going to get out when they don't notice him?"' (Joan, wife)

Even when the person with dementia was not able to leave the site, carers still lived with the fear that they might disappear in the night: 


\begin{abstract}
"I mean the way she used to wander through the night, and we were in separate rooms then, but I have always been a light sleeper, and if she got up, I was up as well, so I wasn't getting any rest... ...I was constantly watching her... ... when she was in the house, the door was always locked, and then it ended up, I got a little dog for her and that seemed to help her because the dog would bring her back, but she would only go across the road, and we have got a little green, and she used to sort of, go round the green, but the dog would drag her back..." (Bill, husband)
\end{abstract}

Indeed, as we have reported previously, sometimes it is the fear of the carers that stops the person with dementia being independent in accessing the outside spaces that they enjoy

Another carer spoke about how the family had to make a decision regarding the care of her grandma because she was constantly 'getting out', and because she did not have any recollection of her husband, she did not want to go back 'home' to him.

"she got to the point where she was getting out and she didn't know who my granddad was, so she then refused to go back home... .... couple of times she got out and she would just flee, basically, and then... ...she'd end up in, like, the neighbours. Who thankfully knew her, they knew my granddad, and she was just like, 'I'm not going back to that house, there's an old man in that house and I don't know who he is.'...... I think it must have been awful because there would have been that fear of, kind of, that natural fear to, kind of, flight, 'cause, like, 'I'm in a situation, I don't know where I'm at, I need to get out.' But equally it's kind of like you, you can't get out because it's not safe for you to be wandering around.” (Sarah, granddaughter) 
The extent and frequency of wandering behaviour is thus often a crucial factor in how carers evaluate if the person with dementia can be cared for at home, or if they need residential care. In the case of Sarah's grandmother, the family decided ultimately that for her own safety, to mitigate the risk of 'her getting out', and for her husband's safety as she had started to be aggressive towards him, that 'settling' her into a residential home was the best decision for all.

These fears of the person with dementia 'getting out' were profoundly linked with the perceived safety of the person with dementia:

\footnotetext{
"She used to ask about her dad quite a lot, and she used to talk about her home in a different place... ...things got bad, I think - bad, whatever that means - when she started getting stressed, but also when she started doing night time walks. That was when things got really concerning... ...the Police came round once as well. They'd found her, one occasion, out, you know, in, in an inappropriate state of dress in very cold conditions. So that - I think that's when it started getting really worrying, and when we really felt that we needed to do a lot more. And, and I think that was - those reports were the beginning of the time when we really started seriously thinking about residential care.” (Kate, granddaughter)
}

Interesting differences are also evident however if we contrast Sarah's experiences with Kate's. In her narrative above, Kate used the phrase 'night walks' for the instances when her grandma walked to her house in the night; note that she does not classify this as 'wandering': 
"Night walks were, yeah. I mean, and I, I imagine I have no idea just how regular they were... ... but then there would be, often, nights where she'd show up at three o'clock in the morning, with her [to your house] - yeah, with her nightie on. So she'd always get in my house - well, I think. She got in my house on a number of occasions... ... she'd show up with her nightie on at three o'clock in the morning, you know. And - or, the neighbours might kind of tell us that they'd seen her going out - they'd ring us - so we'd have to go looking for her." (Kate, granddaughter)

This same woman, once she had moved into the residential home, remained active:

"She helped the cleaners... ... she would kind of keep herself busy pottering about the place... ...she pottered about the corridors and they would often kind of be - direct her back to her bed. But, you know, pottering about your corridors... ... and sleeping in your chair, you know, the next day, it doesn't really matter. It's wandering about in a state of undress when it's minus something outside, in the middle of the night, that is the worry, isn't it? And, and, what happens if you don't manage to get back somewhere? Corridors, what you gonna do? Where are - you're harmless." (Kate, granddaughter)

Kate recounts how her grandma 'pottered around the corridors' and makes a clear distinction between 'pottering' which is 'harmless' and 'wandering' in thin, 'inappropriate' clothes outside in the cold which is a 'worry'. The form of pedestrian activity might be the same, but it is the time, place and conditions under which they occur that make the carer's interpretation of this mobility shift from walking to wandering. 
The use of technologies to prevent the person with dementia being able to 'wander'

Many of the carers recounted examples of times when they did not know where the person they cared for was. Sometimes this transformed their behaviour outside of the home or changed the ways in which they managed within the home, such as ensuring that doors were locked. There was a common thread in the narratives of how carers used locks, the removal of keys, and alarms to ensure that the person with dementia did not get out, particularly at night:

\footnotetext{
"but my Alan... ... in the early stages he used to do some wandering, and I had to get bolts on both sides of the side trellis doors so that he couldn't get out you know, and it was long time when I had to lock the doors and hide the keys and everything, but somehow or other, he used get himself out, and we live right near the seafront at Rowton $^{\mathrm{v}}$ and I used to think 'oh God if he gets onto that main road he would just cross the road', he wouldn't have any traffic sense at all... ... so that's how I, I had to lock the doors, I had to stop him getting out...... [one time when he was in respite care and escaped] the neighbours realised he must be from the [respite] home and they brought him back which was very worrying because that was so near a very main road." (Eileen, wife)
}

"So the, the door alarm is sort of for us, gave us peace of mind that we knew that she wasn't out wandering, that she wasn't gonna get lost and stuff like that." (Cath, daughter)

Joan talks about her husband Fred 'loving to get out' and how he loved walking but that it got to the stage where she simply could not keep up: 
“... he can't go anywhere on his own... ...I mean, he'd just be lost, but he wants to go out the whole time; I mean I get no peace and I have got very bad arthritis so I find it difficult. So if we have been for one walk, I mean a walk of a mile or two mile, that's my limit for that day. But Fred doesn't think so, I mean he will come in, have a cup of tea, and then the sun is still shining so he's putting his coat on, 'come on then, are we going for a walk'... ... and the only way I can get him to stay in is to give him a can of beer, then he will stop in." (Joan, wife)

As Fred increasingly became 'lost' from the club that he used to go to, Joan made the decision to move to a place that she felt was more pleasant to walk around, instead of where they had lived before which to her was just 'streets':

"Before Fred reached this stage, before we moved here, he used to go to the club every day for a pint, and it got to the stage where he forgot the way home and then he forgot how long he had been out and what not, and that was when I decided it was time to move to a different location, because that wasn't conducive to the rest of our lives to live where there was just streets to walk round, so we come down here where it is pleasant to walk, but he can't go anywhere on his own, he has to, that, I mean, he'd just be lost, but he wants to go out the whole time." (Joan, wife)

A different carer spoke about how, even within the early stages of dementia, her mother became distressed when she was unable to get home. She was away all day before being found in a nearby field:

“...we looked frantically all over the place; again we weren’t expecting her to get lost, we thought she is just next door... ...so hours passed and we got the Police and they got the dogs out and we were frantic, thought you know, because she was so 
vulnerable and it was getting... ... quite cold and she just, she had, she didn't have a cardigan on or anything and where she was found...... on the field just around the, behind the back garden, in the school field where the long grass [is]...... and she was crouched down in the grass when they found her, sort of rocking backwards and forwards, she was very, very distressed..." (Angela, daughter)

Taken together, the examples here give some sense of the complexity of what carers are faced with. For instance, the respondent immediately above, Angela, highlights later in her interview the impracticality of existing technologies for finding her mother. Identity cards or bracelets, she points out, would have been ineffective because of her mother's distressed state and the way she was crouched down in a field making it difficult for her to be seen. The lasting impact that this had on this family and the person with dementia was the sharp curtailment of activities because all (including the mother herself) were 'terrified of (her) going out'. Cath, on the other hand, gets peace of mind from the door alarm technology in order to monitor her mother's movements, but Fred's wife's account clearly demonstrates how locks and keys are not always sufficient technologies for carers to control the urge of the person with dementia to be on the move. Strategies used include improvising with everyday household items at hand, in this case beer, and in the section above, the family dog who is relied upon for help, but also more radical changes such as moving home as in the case of Joan who, recognising the changes in her husband, sought a 'better' place to be able to walk in.

Families thus rely on a range of strategies to manage, but more explicit forms of technology have often been viewed as a 'solution' to challenging behaviour such as wandering. In the example below, the use of a mobile 'tracking' technology became the reason why Liz's 
husband was prevented from getting out and about. The technology made Liz aware of how far her husband was travelling and this in turn prompted Liz to replace the 'tracking' technology with a door alarm to warn her when he was trying to get out. Although the 'tracking' technology proved useful when he wandered locally such as into town, it caused fear when on one occasion he got himself on to a bus out of the area. Despite knowing where he was through the tracking device and informing the Police, Liz felt that he was now wandering too far to be safe. This example highlights that the success of the technology, making visible the distances her husband travelled, actually led to its failure. This is because the tracker technology is meant to enable independence, not determine when independence should be curtailed (as it seemed to be in this case):

"It was in that sort of in between stage when we first, first time he just missed the house and disappeared onto the moor. And we found him on the top. Police were very concerned 'cause one day last year, or the year before, a lad was, died on the moor with hypothermia. So this last time, the last time I lost him just sort of locally, he just got out of the house ......Found him on the High Street in the end...... the tracker in the early stages was a comfort, you know, I did like to know where he was at any time. But it always the drawback of what do you do when you do find out where he is? You know, you find he's in the middle of the town moor it's not, it's not easy to know which bit to start looking. They're not exact enough." (Liz, wife)

Thus, in a variety of ways, technologies shape carers' behaviour and decision making. The use of technologies have implications for independent living (which is highly culturally valorised) in that they can both facilitate it and extend it in the home-space. But this goal of maintaining independent living is constantly being balanced up by carers against their fears (both perceived and real) about people with dementia's safety, and also powerful cultural 
norms of familial responsibility when people with dementia can no longer 'be trusted' with their own behaviours.

\section{When wandering is linked to place, including 'home'}

Carers also spoke about places that are known to the person with dementia, whether these are places in their earlier lives or places they loved to visit. Joan below talks about why they moved to the Coast and how her husband Fred loved Rowton, because they always used to go there for holidays. Fred on one occasion escaped from his respite care and journeyed via Train to the Coast where Joan lived in a flat, but unfortunately "he had turned the other way and wandered through" past her street. This had worried Joan because he would have gotten to the seafront and "goodness knows where he would have gone to from there". As she elaborates:

"The first time my husband was in respite, we lost him and he was missing for four hours... ...eventually it was my own son who was out in his car looking and he found him, he had wandered from [town] to Rowton ${ }^{\mathrm{vi}} \ldots$.. (Joan, wife)

Similarly, Jenny, another carer, recounts a time where Richard, her husband, was admitted to hospital. He tells her when she visits that he's 'been for a walk' but Jenny thought he was 'being silly'; there was no way he could have gone for a walk because he was in hospital. However, the sister on the ward informed them later that he had been out of the hospital and was found walking around the car park. Jenny then goes on to speak about the second time this happened; the ward sister rang her at home when Richard had been discovered missing. The sister had said Richard had 'gone walkabout' and that the police had been called, but that she was ringing because "we thought that if he's walking" she said, "he might have walked home". Jenny recounts that she could not believe this would happen as she lives a substantial distance from the hospital and that Richard did not have any shoes, only slippers. Despite 
this, Richard did arrive home, on foot later that day. Jenny, describing how the first thing she asked him was:

\begin{abstract}
“"what are you doing?”, and he said 'I just wanted to come home' ... ... his dressing gown he had on, but he had that on his, over his shoulders, and his eyes were red, because it was freezing cold, it was a freezing cold day, and when I look down, he had his slippers on...... and I thought, they look soaking wet, this whole slipper looked wet, and so we sort of brought him in and put him on a chair and then I said, 'take your slippers off' then we realised, it wasn't water, it was blood. All his feet were just; the skin was hanging off his feet. (Jenny, wife)
\end{abstract}

Richard had navigated the 10 kilometre walk 'getting home' by using all of the familiar places he remembered:

“...he'd gone down through Rowton... ... and he said he had walked along and then he said, 'up by the ice cream place we'd go for a coffee', which was the Seafront cafe, you know, and he had come up that way... ... and then he'd cut through, through Erston because he knew about the Church and he says, 'that place where the Church is'...so he'd used all the back...all the places he'd known..." (Jenny, wife)

Both Joan and Jenny's accounts highlight how 'walking' or 'wandering' in dementia is not always aimless or lacking cognitive capacity, but can be linked to memories of familiar places. Whilst Fred had made a wrong turning when nearly at the flat (and had successfully negotiated nearly 15 kilometres before getting disorientated, including a trip on the Train), Richard navigated his way on foot, relying on familiar landmarks to arrive back at the family home. 


\section{Wanting to go home - to a familiar home}

Paralleled with the material in the previous section, a number of carers touched on the person with dementia 'wanting to go home'. This was often linked to home being a familiar place, even if the 'home' they wanted to go to was one from their past. Joan speaks of how her husband Fred regularly refers to their home but by this he means where they lived before the Second World War:

“... but then he would get his wallet out and he was looking at his wallet and I said, 'what's the matter, what are you looking for?', he says 'I'm just wondering if I have got enough to get back', I says 'to get back where Fred?', and he says 'well home', and I says 'well this is home', 'no, no' he says, 'I mean' he says , and I says 'in any case Fred, you don't pay on the bus now, it's now all free on the bus', I am trying to change the conversation and I said 'put your wallet away, you don't need your money', and he says 'but I have to go, I have to go' and I say 'well look, just go and have a look and you'll see your bedroom, just along there', 'my bedroom's just along there?', 'go on, go and have a look at your bedroom, it's just around there', so I'll say 'leave this door open and I'll make sure you go up the right place', so he opens the door, goes out, comes back and he says 'yes, I have slept in that bed before, I recognise that' "' (Joan, wife).

Tracy on the other hand highlights how whilst she herself worried about her father losing his way, her mother did not share this fear. Instead, she had a confidence that her husband would make it back home:

"when [my dad would walk to the shop] I worried myself silly, "Has he got lost?" She never did, she was always confident he would find his way home. And he always did, 
but it worried the heck out of me because I was thinking, 'Oh my God', you know..." (Tracy, daughter).

Tracy elaborates that "it took my my mum a long time to sort of understand what he was able to do and what he wasn't able to do", but her mother had a certainty, born out by experience, that her father could navigate successfully home. Similarly, Cath, below, highlights the "panic" she felt when her mother went missing, but she also felt that her mother would be able to get back home because she always managed to, although on this occasion she didn't make it home but made it back to the spot she had become detached from her family:

“I was absolutely beside myself, because I didn't know whether she would, she was also always very good at actually getting home. She was, she knew how to get home. So we went down to our old home, because she was at my house, so and stuff like that. But she just wasn't there, but she managed to get herself back to where she started. I don't know how she did it." (Cath, daughter)

\begin{abstract}
'Home' is obviously not a straightforward category: in Fred's case, for instance, the passage of time is collapsed and his desire to go home does not map onto his current residence, but instead onto one from many decades prior. Having said that, all the examples above underline the strength of attachment to a familiar home, and how many carers' recognised this significant relationship as enabling people with dementia to navigate back.
\end{abstract}

\title{
Discussion
}

Firstly, throughout the narratives around the experience of 'wandering' or the person with dementia becoming 'lost', the carers demonstrate the importance of a range of intersecting 
strategies necessary to enable them to manage and care for their family members who exhibit agitated behaviours associated with dementia. These include assistive technologies such as door alarms, GPS tracking devices and identity cards. But they also include the wider social networks the people with dementia are part of whereby some neighbours 'informally' monitor their activities and raise alerts. Additionally, there are also the everyday, improvisational domestic resources such as the family dog who "would drag her back"; and Fred's wife's "can of beer" when she is not physically able to do a second walk in the same day. As such, what is evident here are the ways in which multiple, intersecting levels of technology are employed to manage both the behavioural characteristics of the person with dementia but also the responsibilities and fears of the carers. Having said that, what is also evident is that these strategies and technologies become part of the process of identifying for the carers when walking has become wandering, or when wandering has become 'too dangerous' and needs to be curtailed. Unintended consequences can follow from this whereby technologies meant to extend or facilitate independence end up limiting independence by redefining non-normative walking as dangerous, rather than as a manageable activity.

Secondly, evident in the carers' narratives about wandering are the specificity of local landscapes and places. On the one hand, this is a source of consternation and fear. Carers talk about a number of topographical features in their accounts above: main roads, road crossings, a school field with long grass, the bus station and the sea front. Many (although not all) of their fears are linked to aspects of place that might make them particulary threatening. But on the other hand, places and travelling between them feature importantly in the trajectories and pedestrain trips the same carers report for the people with dementia. This reoccurring thematic of place strikes us as particularly pertinent in our attempts to answer when walking becomes wandering. We return here to Edensor's (2010) point about rhythms, walking and 
embodied relations with place above, and ask if there might be some mileage to be gained by thinking about wandering and embodied relationships with place. On the one hand, it seems to us that carers perceive wandering as threatening due to an apparent lack of rhythm and intent ('aimless', in the healthcare literature), and that it is this they feel tips walking over into wandering. But the accounts above push us to ask if the pedestrian activity of some of these people with dementia also have a rhythm, which is an alternative, non-normative form of rhythm, a rhythm that is linked to place.

Ingold (2004), writing about walking and seeking to escape the Cartesian binary of mind versus body, helps us make this argument. He encourages us to think about walking as a form of intelligence that is not simply in the mind. Instead, he posits an intelligence that is "distributed throughout the entire field of relations comprised by the presence of the human being in the inhabited world" (2004: 332), or as Bean et al put it, how "walking internalises the relationship between the body and place" (2008: 2837). In a number of instances above, individuals are wandering to known places such as their homes or favourite locations. It is precisely this that attests to the "relational field(s)", the "embodied capacities of movement" (Ingold 2004: 333) that the person with dementia continues to be enmeshed in, despite assumptions that the person with dementia is no longer able to engage in such sorts of relations. It appears then in these cases at least that the person with dementia does indeed have a walking intelligence, one that "is not located exclusively in the head" but which is instead part and parcel of the person's relationships with place (Ingold 2004: 332). We must not, however, sugar coat this - we recognise the very real fears around wandering for carers and people with dementia themselves, and also some of the distressing consequences. But we want to call attention to how our data on how place still matters in these examples of wandering, and how it pushes back against the damning, limited, binary stereotypes about the disappearance of mind and thus of person. 
Thirdly, there is the issue of how both wandering and the person with dementia should be associated with a pathological mind/body relationship. We said above that it is not coincidental that walking should be associated with the thinking, modern self and that wandering by the person with dementia should be associated with a problematic mind/body relationship. This is inextricably due to Cartesian dualism of mind/body which frames western understandings of the world. This binary firstly posits the self as residing in the mind (a cognitive model of self) and secondly resists the possibility that self and identity might also be at least partially embodied (a corporeal understanding of the self) (Kontos, 2003, 2005). Drawing inspiration from the work of Kontos, we contend that recognising "the irreducibly embodied nature of human subjectivity and agency" (2003: 152) helps reveal the cultural assumptions at work in the shift of when walking comes to be described as wandering. Walking is understood to be possible when the mind and body work together correctly, whilst wandering is perceived as when the mind is 'lost' and the body takes over. These underpinning assumptions of the dualism of mind/body are also evident in the healthcare literature in the debates we summarise above about behaviour associated with wandering, and if the movement of the person with dementia is 'aimless' or 'directed' (Snyder et al 1978, Algase et al 1997, Halek and Bartholomeyczik 2012). A good example of how these assumptions are reproduced in everyday life comes from the grandaughter's account above where she describes her grandmother's locomotion as 'night walking' and not 'wandering', seemingly because her grandmother's night walking is intentional and rational as it leads to her grandaughter's house due to the relations and memories lodged there. Similarly, the same grandaughter distinguishes between 'harmless' 'pottering around' and wandering in that the former is unthreatening and not destabilising or in need of control. 
This contrast between walking (with the implicit connotation of a healthy mind/body relationship) and wandering (with an implied pathological mind/body relationship) becomes even clearer if one considers other forms of the 'wrong kind' of walking, such as shuffling: “adopting a shuffling gait ... is widely regarded as a mark of impotence, infirmity or decrepitude" (Ingold 2004: 324). Here, finally, we come to the nub of the matter: the abject figure of the fourth age, the emergent "event horizon" of "mindlessness and immobility" (Higgs and Gilleard: 2015: 16-17) in the social imaginings of dementia whereby the mind is, purportedly, entirely subsumed by the body. This non-normative, 'decrepit' figure is virtually absent from the literature on walking for it is assumed that wandering is in and of itself evidence of the no longer mindful state of someone with dementia. This circular logic then becomes nearly impossible to disrupt or challenge, and instead becomes self-fulfilling in the social imaginary.

In conclusion, there are clear parallels between the ways in which the mind/body split is conceptualised when analysing walking and when analysing selfhood in dementia. That is to say that ideas in the west about walking are clearly complicatedly bound up with Cartesian dualisms of mind and body. So too are ideas around selfhood in people with dementia and the idea of mind being overcome by body. Wandering - a wrong kind of walking - is interpreted as collapsing the division between head and heels ${ }^{\mathrm{vii}}$, mind and body. Dementia is understood as irretrievably collapsing this divide, with 'body' coming to completely overtake 'mind', and little possibility in the social imagination for reclaiming meaning or intentionality, as those are assumed to be simply cognitive matters.

Such cultural assumptions are encoded in understandings of the shift when walking becomes wandering in western cultures. In response, we contend that "confining what is essential about selfhood to the brain is to overlook how bodily sources of agency, grounded in the pre- 
reflective level of experience, are fundamental to the constitution and manifestation of selfhood and Alzheimer's disease" (Kontos 2005: 555) and that significance must also be granted to the body and embodied agency in a person-centred approach to dementia (Kontos 2005). The data we present here on the importance of place and embodiment is an important corrective to these assumptions about when walking becomes wandering, and are an important consideration of a non-normative form of mobility. As our data demonstrates, wandering is not a term that can easily be dispensed with: it is a concept that carers use in their everyday lives to try and describe and explain behaviours that are very worrying to them. But simultaneously, by using this term, all the associations it conjures up of the person with dementia being 'aimless' and unable to meaningfully travel on foot reinforces the negative and dehumanising notions we have about dementia and about a supposed disappearance of mind and self. Our data, based on the experiences of carers, challenges the simplicity of this equation by highlighting where it is people are wandering to.

\section{References}

Andrews, G.J., Hall, E., Evans, B. and Colls, R. (2012) Moving Beyond Walkability: On the Potential of Health Geography. Social Science and Medicine 75, 11, 1925-32.

Balestreri, L., Grossberg, A. and Grossberg, G.T. (2000) Behavioral and psychological symptoms of dementia as a risk factor for nursing home placement. International Psychogeriatrics 12, 1, 59-62.

Bean, C., Kearns, R. and Collins, D. (2008) Exploring social mobilities: narratives of walking and driving in Auckland, New Zealand. Urban Studies, 45, 13, 2829-48.

Brittain, K.R., Corner, L., Robinson, A.L., Bond, J. (2010) Ageing in place and technologies of place: the lived experience of people with dementia in changing social, 
physical and technological environments. Sociology of Health and Illness. 32, 2, 272-87.

BSG (2008) British Society of Gerontology Guidelines on ethical research with human participants.

Chan, D.C., Kasper, J.D., Black, B.S. and Rabins, P.V. (2003) Prevalence and correlates of behavioural and psychiatric symptoms in community-dwelling elders with dementia or mild cognitive impairment: The Memory and Medical Care study. International Journal of Geriatric Psychiatry, 18, 2, 174-82.

Cipriani, G., Lucetti, C., Nuti, A. and Danti, S. (2014) Wandering and dementia. Psychogeriatrics, 14(2), pp.135-142.

Cohen-Mansfield, J. (1986) Agitated behaviors in the elderly. II. Preliminary results in the cognitively deteriorated. Journal of the American Geriatrics Society, 34, 10, 722-27.

Degnen, C. (2012) Ageing Selves and Everyday Life in the North of England: Years in the Making. Manchester: Manchester University Press.

Department of Health (2009) Living Well with Dementia: a National Dementia Strategy. London: Department of Health.

Dewing, J. (2006) Wandering into the future: reconceptualizing wandering 'A natural and good thing'. International journal of older people nursing, 1(4), pp.239-249.

Edensor, T. (2000) Walking in the British Countryside: Reflexivity, Embodied Practices and Ways to Escape. Body \& Society. 6, 3-4, 81-106.

Edensor, T. (2010) Walking in rhythms: place, regulation, style and the flow of experience”. Visual Studies, 25, 1, 69-79.

Gibson, G., Dickinson, C., Brittain, K., \& Robinson, L. (2015). The everyday use of assistive technology by people with dementia and their family carers: a qualitative study. 
BMC Geriatrics, 15, 1, 89.

Gilleard, C., and Higgs, P. (2011) Ageing abjection and embodiment in the fourth age. Journal of Aging Studies, 25, 2, 135-42.

Glaser, B. (1965) The constant comparison: methods of qualitative analysis. Social Problems, 12, 4, 436-45.

Halek, M. and Bartholomeyczik, S. (2012) Description of the behaviour of wandering in people with dementia living in nursing homes-a review of the literature. Scandinavian journal of caring sciences, 26(2), pp.404-413.

Higgs, P. and Gilleard, C. (2015) Rethinking Old Age: Theorising the Fourth Age. London: Palgrave.

Ingold, T. and Vergunst, J. (2008) “Introduction". In: Ingold, Tim and Vergunst, Jo (eds) Ways of Walking: Ethnography and Practice on Foot. Farnham, Surrey: Ashgate.

Ingold, T. (2004) Culture on the Ground: The World Perceived Through the Feet. Journal of Material Culture, 9, 3, 315-40.

Klein, D.A., Steinberg, M., Galik, E., Steele, C., Sheppard, J.M., Warren, A., Rosenblatt, A., Lyketsos, C.G. (1999) Wandering behaviour in community-residing persons with dementia. International Journal of Geriatric Psychiatry, 14, 4, 272-79.

Kontos, P. (2003) "The painterly hand": embodied consciousness and Alzheimer's Disease. Journal of Aging Studies, 17, 2, 151-70.

Kontos, P. (2005) Embodied selfhood in Alzheimer's Disease: rethinking person-centred care, Dementia, 4, 4, 553-70.

Lai, C.K., and Arthur, D.G. (2003). Wandering behaviour in people with dementia. Journal of Advanced Nursing. 44, 2, 173-82. 
Michael, M. (2000) These Boots are Made for Walking...: Mundane Technology, the Body and Human-Environment Relations. Body \& Society, 6, 3-4, 107-26.

Middleton, J. (2009) 'Stepping in time': walking, time, and space in the city. Environment and Planning A, 41, 1943-61.

Middleton, J. (2010) Sense and the city: exploring the embodied geographies of urban walking. Social and Cultural Geography, 11, 6, 575-96.

Middleton, J. (2011) Walking in the city: the geographies of everyday pedestrian practices. Geography Compass, 5, 2, 90-105.

Moreira, T. and Bond, J. (2008) Does the prevention of brain ageing constitute antiageing medicine? Outline of a new space of representation for Alzheimer's Disease. Journal of Aging Studies, 22, 4, 356-65.

Nelson, M.E., Rejeski, W.J., Blair, S.N., Duncan, P.W., Judge, J.O., King, A.C., Macera, C.A., Castaneda-Sceppa, C., (2007). Physical activity and public health in older adults: recommendation from the American College of Sports Medicine and the American Heart Association. Circulation, 116, 9, 1094-105.

Phillips, V.L. and Diwan, S. (2003) The incremental effect of dementia-related problem behaviours on the time to nursing home placement in poor, frail, demented older people. Journal of the American Geriatrics Society, 51, 2, 188-93.

Rowe, M.A. and Glover, J.C. (2001) Cognitively impaired individuals who become lost in the community: A descriptive study of safe return discoveries. Alzheimer's Disease and Other Dementias, Nov/Dec, $1-9$.

Snyder, L.H., Rupprecht, P., Pyrek, J., Brekhus, S. and Moss, T. (1978) Wandering. The Gerontologist, 18(3), pp.272-280. 
Spinney, J. (2010) Cycling the city: movement, meaning and method. Geography Compass 3, 2, 817-35.

White, E.B. and Montgomery, P. ( 2014) A Review of "Wandering" Instruments for People With Dementia Who Get Lost. Research on Social Work Practice, 24(4), pp.400413.

Wick, J. and Zanni, G. (2006) Aimless excursions: wandering in the elderly. The Consultant Pharmacist, 21(8), pp.608-618.

Van den Berg, H., (2008) Reanalyzing qualitative interviews from different angles: The risk of decontextualization and other problems of sharing qualitative data. Historical Social Research/Historische Sozialforschung, pp.179-192. 
i As will become apparent, 'wandering' is a term and a concept that we seek to examine critically in this paper. As such, it is a term that we understand here as problematic and so have placed it in scare quotes to indicate our questioning of the concept. For ease of reading however, we do not continue to use scare quotes after this point in the text but the reader should be clear that we hold it in question throughout.

ii See Middleton (2011) and Andrews et al (2012) for valuable summaries of the extent of cross-disciplinary perspectives on walking.

iii We recognise that 'Western' is a falsely heterogenous category which obscures a great deal of cultural variation. However, it also provides a useful shorthand for describing some of the shared worldviews shaping this material and our analysis of it, which is why we use it (with reservations) in this article.

${ }^{\text {iv }}$ We have termed this a secondary analysis, as the research design and data previously collected ( was revisited and analysed by two of the authors

). One of the challenges of carrying out secondary analysis within qualitative research is retaining the original context of the data collected when new questions are asked of it (see van den Berg 2008 for an in-depth discussion on this). In this instance such a risk of de-contextualisation was mitigated by personal involvement in the research design, data collection and analysis of the original studies.

${ }^{v}$ The name of the coastal town and the café included in this paper have been replaced with pseudonyms, as have the names of the particpants, so as to ensure that participants are not identifiable. However, in doing so we recognise again the importance of place.

${ }^{\mathrm{vi}}$ A distance of about 14.5 kilometres.

vii We are indebted here to Ingold (2004: 315) for this expression of 'head over heels' in regards to the relationship of mind and body in Western thought. 